\title{
9 POSSIBILITIES AND CHALLENGES OF TRANSITION TO AMBULANT HEALTH SERVICE DELIVERY WITH ICT SUPPORT IN PSYCHIATRY
}

\author{
Synnøve Thomassen Andersen \\ Finnmark University College \\ Alta, Norway \\ Margunn Aanestad \\ University of Oslo \\ Oslo, Norway
}

\begin{abstract}
Transformations of established institutional orders are to be expected alongside the appearance of novel ICT-enabled models of service delivery. Such transformations are neither simple nor short-term, but involve complex and fundamental changes in normative, regulative, and technical aspects. In this paper we describe the initial stages of a project redesigning psychiatric services for children and adolescents. New collaboration models, supported by new ICT applications, were introduced into the ordinary structures of health care services in Finnmark, the northernmost county of Norway. Our aim is to contribute to the understanding of how the preexisting technical and organizational systems and models, the installed base, impact radical change. We address the potential for user-driven innovations, and focus our analysis on the quality of generativity in the existing information infrastructure. The salient challenges in our case were related to the existing technical information infrastructure in the health sector. The new solution was pushed outside the established information infrastructure. While this may be only a temporary situation, we argue that, as a result of this process, the new solution emerged with a greater potential for future generativity than it would have had it been more linked to the existing information infrastructure.
\end{abstract}

Keywords Health care, psychiatry, mobile technologies, installed base, generativity

Please use the following format when citing this chapter:

Andersen, S. T., and Aanestad, M., 2008, in IFIP International Federation for Information Processing, Volume 267, Information Technology in the Service Economy: Challenges and Possibilities for the $21^{\text {st }}$ Century, eds. Barrett, M., Davidson, E., Middleton, C., and DeGross, J. (Boston: Springer), pp. 129-141. 


\section{INTRODUCTION}

The shift to a service economy is pervasive in many sectors, not the least the health care sector. The shape of this trend in many Western countries is to emphasize decentralization and patient empowerment, motivated by the realization that future care models must change in order to be economically feasible and sustainable. In particular, patients with chronic diseases should be allowed to manage their diseases themselves as far as possible. This draws strength from the findings that the mobilization of a patient's own resources, as well as family and community resources, contributes significantly to the healing process (Ball and Lillis 2001; Brennan and Safran 2003). The trend also coincides with current management practice, oriented towards achieving quality and efficiency improvements through market mechanisms, with a client or customer focus. Information and communication technology systems are expected to be crucial elements in such a redesigned health care sector, enabling a shift from a provider-centric model of service delivery to a more flexible configuration of services.

However, introducing novel collaboration forms and technologies into existing structures is challenging. A domain such as the health care sector is comprised of wellestablished institutional orders supported by regulation, administrative procedures, as well as large-scale, complex networks of communication technologies. When new ICTenabled models of service delivery are introduced, they have to be accompanied by transformations in the normative, regulative, and technical aspects. The research questions we address in this paper relate to this tension between radical change and inertia: How do such ICT-triggered transition processes play out in practice? In particular, how much room is there for user involvement in these processes, and what are the effects of this involvement?

In order to conceptualize this, we draw on the theoretical perspectives associated with studies of information infrastructures: large scale, complex, and networked information and communication technologies (Hanseth and Lyytinen 2004). We focus on the notion of an installed base that emphasizes the historical evolution of an information infrastructure from some preexisting and inherited socio-technical legacy system. Moreover, we bring in the notion of assemblages (Lanzara 2008; Sassen 2006), which can help us to emphasize the normative and institutionalized dimensions associated with information infrastructures. Since our focus is on the potential for users' contribution in change processes, we complement this literature with the concept of generativity (Zittrain 2006), which presents some aspects that make a technological system more or less open to third-party innovation. In the following section we present the theoretical framework for our study. The research methods are then presented, followed by the case study. In the analysis section, we focus on the limited generativity of the previous assemblage, and the effect as well as the potential of this on the change process discussed in this paper. The conclusion is presented in the final section.

\section{THEORETICAL FRAMEWORK}

In order to explore the possibilities for intervention and change in large-scale, sociotechnical networks, we need theoretical resources. Some useful concepts such as 
installed base, assemblage, and generativity are briefly presented in the following sections.

\subsection{Information Infrastructures, Assemblages, and Installed Base}

Information infrastructures denote large and complex networks of information systems and communication technologies (Monteiro and Hanseth 1995). The concept of information infrastructure should not be taken to indicate only the technical components, but to also include social and organizational elements (e.g., work practices, routines, regulations) (Star and Ruhleder 1996). Information infrastructures have attributes that make them different from traditional, standalone IT systems. As an information infrastructure grows, it may acquire momentum (Hughes 1983) and become increasingly entrenched and irreversible. Concepts from the field of network economy used to explain this include self-reinforcing effects, path dependence, and lock-in (Arthur 1989; David 1985). Due to its emphasis on historical development, the notion of an installed base is central within this perspective. Information infrastructures evolve from and are conditioned by what is already in place. For instance, legacy systems as well as sociotechnical institutions, regulations, and procedures can significantly shape the evolving information infrastructure. The installed base is a central resource for any change attempt; it is what facilitates and enables evolution through extension or substitution. On the other hand it can be an obstacle, resisting change due to lock-in. One has to design both "with" and "against" the installed base at the same time.

This approach conveys an understanding that the traditional control-oriented strategies have their limits and calls for different approaches to design (Hanseth et al. 2001). Incremental, evolutionary, and bottom-up approaches are seen as more appropriate approaches, as they are more sensitive to the installed base, exploit the selfreinforcing mechanisms (such as bootstrapping; see Hanseth and Aanestad 2003), and are geared toward avoiding lock-in situations (Hanseth and Lyytinen 2004; Monteiro 1998). However, in emphasizing the limitations of traditional design approaches, this literature may have downplayed other aspects. A recent study of innovation in the mobile sector stated that "existing conceptualization portrays information infrastructures as autonomous and under-theorizes the multiplicity, the agency and the interrelations between information infrastructure builders and their institutional context in building processes" (Nielsen 2006, p. vii). Thus we argue that we also need to conceptualize the institutional context in which information infrastructures develop.

On the one hand, existing solutions, prevailing routines and social institutions may be entrenched and cannot be changed in an instant. On the other hand, the evolving information infrastructure may enable entirely new constellations and arrangements of agencies. The notion of assemblages has been used to denote how technical communication networks and political, institutional, and organizational entities are imbricated (Lanzara 2008; Sassen 2006). In public sector administrative practices, institutional configurations and ICT are becoming intimately intertwined. The notion of assemblage points to the resulting loosely structured institutional ecology of multiple heterogeneous actors, such as political authorities, bureaucratic organizations, ICT providers, and technical agencies. Each of these act according to their own logic, which may not overlap. Change derives from and is conditioned by older capabilities, material orders, institutional conditions, and technological infrastructures. 


\subsection{Making Room for Users: Generative Technologies}

We also want to focus on the need for user or other third-party participation in the design process. There is a popular belief that radical change in the way health care is offered is more likely to come from a demand- or needs-driven development (i.e., from the clients or patients) than from reforms to health care services "from within." These arguments have their parallel in information systems. For instance, Ciborra (1994) argues that grassroots-driven change is more likely to lead to radical innovation than topdown driven projects. Here, the "establishment" on the top is eager to preserve the status quo, while more marginalized actors are in a position where they have less to loose and more to gain. Without fully buying into these arguments, our goal is to examine the space available for users to be involved in infrastructural change activities.

Studies show that different technologies and different development models facilitate this to varying degrees. Abbate's (1994) comparison of the Internet model with the telecom model showed that different configurations allowed for different usages and different paths of evolution. The Internet turned out to be an enormously flexible platform for multiparty innovation due to its simple network protocols, end-to-end intelligence, and open development processes. In describing the Internet's unprecedented growth and innovation (and the backlash against this), Zittrain (2006) employs the notion of generativity. He suggests that rather than talking about open versus proprietary technologies, we should consider generative versus closed configurations of technologies. Technologies classified as generative (such as the Internet) are technologies that remain open to third-party (user) innovations. Rather than going into his argument about the future of the Internet, we will utilize his definition of generativity as a function of four aspects. A technology is generative if it has (1) capacity to leverage a set of possible tasks, (2) adaptability to a range of different tasks, (3) ease of mastery, and (4) accessibility. The first aspect, leverage of tasks, is related to whether the technology makes the task easier. A very generative technology will allow a lot of effort to be saved, and/or allow effort to be saved on a lot of different tasks, not just one. The second aspect, adaptability, may relate both to use flexibility, whether the technology can be used as it is for different things, and to change flexibility, whether it allows changes to be made. The third aspect, ease of mastery, denotes the ability of the technology to avail inexperienced users to take advantage of it, at least partly. Accessibility, as the fourth aspect, signifies the degree to which a person can come to use and control technology. This includes the ease with which the necessary knowledge can be obtained. Accessibility can be influenced by financial, legal, secrecy, or scarcity barriers. According to Zittrain, the generativity of technologies increases the possibility that users can generate new and valuable usage patterns that become sources for further innovations.

\section{RESEARCH METHODS}

We present the findings of a study of the redesign of psychiatric services for children and adolescents, and describe the challenges and opportunities encountered during the initial project period. In this section, we elaborate on the research strategies used to gather empirical material. 


\subsection{Background Information about the Research Site}

This study was conducted in Finnmark, the northernmost county in Norway, with a population of around 73,000 inhabitants. Out of these, approximately 20,000 are under the age of 20. In 2007, there were 950 children under the age of 18 receiving daily treatment in clinics for children and youth psychiatry (CYP). CYPs in Finnmark employ 50 or 60 persons. The county is 48,649 square kilometers, slightly larger than Denmark, and it is sparsely populated, as only 40 square kilometers ( 0.8 percent of the area) is inhabited. Consequently there are long distances between communities and, for most inhabitants, long distances to the nearest hospital or medical expert. The ICT infrastructure in the county is uneven, with some areas well covered by both broadband networks and telephone networks, other almost without any coverage at all.

The project described in this paper is called "Come Here! - ambulant teams and technology." It was established on January 1, 2006, following a decision in the county's health authority to close down the only psychiatric hospital on July 1, 2005. The hospital was to be replaced by a decentralized model, where ambulant teams would conduct and support home-based treatment for both families and children (between 6 and 12 years). The project was started in order to develop and implement suitable technologies to support this new decentralized care model, with the hope that this might reduce waiting time and the need for hospitalization. The project will end December 31, 2008, after which the model will become the standard for psychiatric care for children and adolescent youth. Four communities were selected as pilots. At the time of writing, the training of users had been completed and deployment of the prototype solution was starting.

\subsection{The Action Research Project}

The first author has been the project manager in this project since its start and, as such, she has been directly involved in the work to develop and implement mobile technology. At the same time, she is pursuing a Ph.D. focusing on the change processes around this project. For this reason the action research method has been deployed in the project. In information systems, action research is a well-known methodology (Baskerville 1999; Checkland 1991; Susman and Evered 1978). A central premise in action research is to include people in the research domain, with the aim of changing the field in ways that both correspond with and challenge tradition. Even though this paper does not emphasize the action research process, this approach strongly influenced the way empirical material was gathered (see section 3.3) and comes with certain challenges that we will briefly discuss.

Action research gives unique access to the field as it allows intimate participation in core processes during the entire project. In addition, the researcher's role is more engaged as compared to a traditional observer. This implies the need to go beyond merely observing and describing from the researcher's own standpoint, to being able to understand, incorporate, represent, and negotiate the other participants' standpoints as

${ }^{1}$ The Norwegian title, "Kom hIT - ambulante team og teknologi," includes a pun through capitalizing IT in hit (meaning here). 
well. As such this approach comes with an in-built validity check. The action research process is challenging, as it involves more work than an observational study, including supporting the process, keeping it on track, and activities to facilitate shared learning. Moreover, it entails challenges in balancing research interests with the practical needs of the project. There may be divergent interests between the role as a researcher and as a change agent, and it may be difficult to be fundamentally critical if one believes in and fights for the project's goals. In this paper, we are not assessing the solution or the change process as such, as these matters would have necessitated a longer discussion. We provide an account of concrete and publicly known events in the project's history, and believe that this makes the study less prone to biased representations.

\subsection{Empirical Material Used in This Paper}

The orientation of the action research project (to stimulate and facilitate user innovation) thus has defined the focus of this paper. The approach has also shaped the methods for collecting data, to which we now turn.

In the role as project leader, the first author has participated in multiple project activities which have generated the empirical material for this paper. A significant source of data is observations during formal meetings. There have been a total of 11 project team meetings, 9 steering group meetings, 5 meetings with contractors, and 4 meetings in the smaller "techno-group." The discussions and decisions from the meetings were documented by the researcher/project leader through extensive note-taking. The participants were aware of the project leader's research plans, and did not appear uncomfortable by her note-taking. The notes were then written up, shared, and discussed with the administrative participants, the project team, and the techno-group. The notes were examined by the meeting participants and were mostly accepted; only twice were revisions necessary. Another important data source was other documents produced during the project period, for instance, the project description (in several versions), summons, reports, letters, and contracts. Around 70 formal project documents and literally hundreds of e-mail messages have been produced during the project work so far. In addition, the first author has conducted three courses in using the mobile solution for the ambulant teams, the CYP specialists, as well as teachers, parents, and children. Moreover, during the initial phase (2006), four interviews with two officials from the CYP service and two representatives from the user organization, Mental Health, were conducted, focusing on gaining an understanding of the current situation.

\section{CASE: "COME HERE! - AMBULANT TEAMS AND TECHNOLOGY"}

Health Finnmark (the county's public health authority) established the project January 1, 2006, in order to develop and implement suitable technologies to support a new decentralized care model, and analyze if this model might reduce waiting time and the need for hospitalization. Thus the project was well anchored at the management level of authority. The health authority appointed the leader of the Clinic for Psychiatric 
Health and Inebriation to collaborate with the project leader. During the first half of 2006, three meetings were held with the employees in the clinic and the ambulant teams. Tentative project descriptions were sketched and revisions discussed during this period. The final project team was established October 5, 2006, and consisted of the project leader, one member from each of the two ambulant teams, one member from the IT department in the county's health authority, and two members from the user organization, Mental Health. The project group decided to have a strong focus on user participation. The term users in this case means health care workers (CYP team members and CYP specialists) as well as parents, adolescents, and children.

When the project started, two important decisions had to be made: selecting the professional method and selecting the technology. The professional team decided to use the treatment method called the Parent Management Training - Oregon model. The PMT-O is an outpatient treatment model for parents with children that are difficult to raise. The method presupposes structured and intensive work to change the child's behavior, focusing on the behavior and situation in the family, at school, and in the community. The method aims at training parents to cope with and raise their child in a better way. During the initial meeting, the team, parents, and child define and prioritize the goals to be reached. Then they negotiate specific behaviors that should be encouraged or discouraged (for instance in relation to behavior during mealtime or when going to bed). The child's rewards in relation to these action points are defined, as well as how many scoring points certain behaviors should entail. Based on this, a reporting form is created. Parents in cooperation with the child are supposed to register the behavior and assign a score (between zero and five points) frequently, for example, during every meal or every evening when going to bed. These reports are the basis for the interaction between the family and the CYP team. Between the visits by the ambulant team, the parents should register the behavior. When this model was implemented, some parents would fax the forms to the team, but others kept the forms until the next time they interacted with the team. It was felt that this collaboration would benefit from more frequent reporting as well as enable easier and more frequent interaction. The project aimed at changing these communication patterns by introducing technology that let parents report on and register behavior immediately, allowing the CYP team to monitor progress on an ongoing basis.

Choosing the technology was the other component necessary in order to reach the project's goals. The health authority contacted the Norwegian Center for Telemedicine (NST) for advice on choosing suitable technology. While the NST proposed using videoconferencing technology on PCs, the steering group and the project team felt that thirdgeneration mobile technology was more suitable. The arguments in favor of mobile technologies were multiple: A technical solution based on video-conferencing had high costs. The cost of purchasing mobile phones would be moderate as compared to the purchase of PCs, web cameras, document cameras, etc. Such a solution might also require costly upgrades of the different studios of the out-patient clinics. Moreover, the ambulant teams were traveling a lot, and mobile phones would therefore be more practical communication equipment than portable PCs. Coverage of the mobile network is also better than coverage of the broadband network in the northern part of Norway. The training required for children, families, and ambulant CYP teams in order to use the video-conferencing solution was comprehensive, while knowledge and use of mobile phones is widespread in most every age group and every social layer of the population. 
The decision to go for mobile technologies was made early in the project period, at the second project meeting. At that time, the NST did not have competency on $3 \mathrm{G}$ technologies, and thus the project continued without their formal participation.

The decision to use mobile technology was followed by an unexpected reluctance from the IT department. One participant from the IT department was appointed to the project group, but was not active in providing information requested. The IT department formally withdrew from the project in January 2007, nearly a year after the project started. The argument for withdrawal was related to the reorganization from January 1, 2006, in the regional health authority (Northern Norway Regional Health Authority, which manages health care in Finnmark and two other counties). During this reorganization, the IT divisions of the health authorities for the counties were centralized into one regional IT department. As this project was initiated on a county level, the regional IT division required extra resources for participating and servicing the project. The project did not have these extra resources, and the effect of this was that the project team continued without participation from the IT department. Despite multiple requests, the project team also did not receive technical information about the existing information infrastructure, the Norwegian Health Network, which is a broadband network connecting all health institutions. With support from the project group, the project leader developed the requirement specifications for the project using mobile technology and a customdeveloped application. However, this situation lead to the project being alone in choosing and shaping the solution. This had some important consequences. On one hand, it allowed a lot of room for adapting to the wishes and needs of the users in terms of communication patterns and functionality. On the other hand, the project explicitly emphasized building a flexible solution; this was due to the lack of information about the existing technical infrastructure.

An application that supports the PMT-O model was developed with user participation and is now implemented on mobile phones. The application (based on J2ME, version midp2.0) is called "Come Here! MOBILE" and is implemented on Nokia E65 phones that are distributed to project participants. This application is a replication of the paper forms used to register the results on specific action points regarding the child's problems. The application is general, but adaptable in order to give every child and family the possibility to adapt it to the individual case management plans (see Figure 1). The data sent from the phone (e.g., a list of scores or a report on behavior during meal time) is transmitted over the GPRS/UMTS network, using the HTTPS protocol (with 256 bits encryption). All data are stored in an MSsql database and an IIS server, using the .Net platform. There is no local caching, so no sensitive data is saved on the phones. A general assessment of security issues and a risk analysis was performed by a consultant from KITH (the Norwegian Competency Center for Health Care IT), who concluded that the solution complied with the legal requirements. The CYP workers have access to the information from the server (which is located at the technology vendor's facilities) through Internet and virtual private network (VPN) channels. As this is outside the secure healthcare network, there is no direct import into the main patient record application, but it is possible to cut and paste information from the application into the "CYP Data," which is the main patient record application.

The project's anchoring in the top level management of the Health Finnmark authority implied that necessary changes related to administrative routine were accom- 

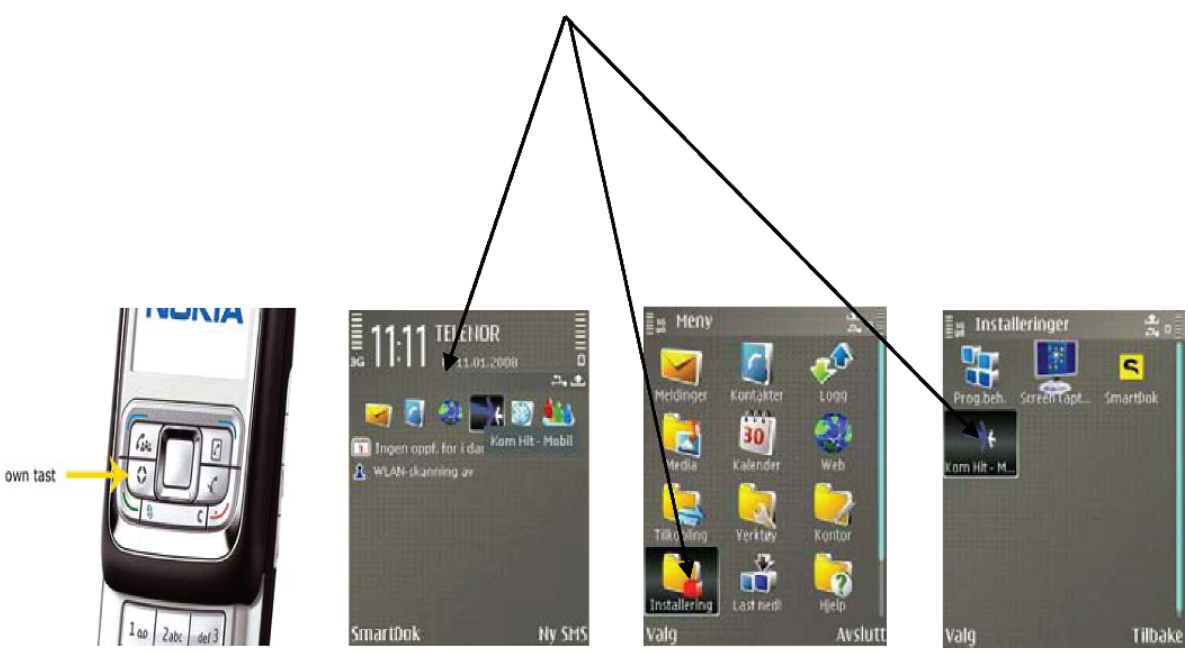

Figure 1. Three Ways to Start the Application (Dedicated Button, List of Programs, or Icon)

plished. These changes were not trivial, and related to defining new contract types, new models for purchase agreements, and new types of service models. For instance, the type of telephone subscription schemes and reimbursement models were discussed. However, these issues were resolved during the project period. The larger challenge remained, and decoupling from the IT department has still not been addressed satisfactorily.

In January 2008, the IT department responded with an assessment of the project's solution. Several critical comments were expressed, most of them relating to security and confidentiality issues. Specifically, the IT department commented that this solution presupposed direct IP-connectivity between the health network and the outside Internet; which was explicitly not permitted. Moreover, it allowed for a transaction being initiated outside the health network, while the current regulation says all transactions should originate within the secure health network (a pull rather than push-based communication pattern). The type of encryption selected also was not perceived to be sufficient. The IT department discussed the tradeoffs of a possible solution. If the solution was placed in a "demilitarized zone" outside the hospital, it would encounter legal challenges related to the storage of sensitive health data. Alternatively, a message-based solution could be placed inside the health network, but that would come with some lag in communications. While this description reflects the current situation at the time of writing, we expect that a permanent solution offering inclusion and coupling to the existing health network will be found before the project ends.

\section{ANALYSIS AND DISCUSSION}

Earlier, we presented the empirical material illustrating how the process of designing the new infrastructure was influenced by the contingencies and the resulting assemblage 
of actors. Concretely, two important factors were the lack of access to and information about the existing health network, and the fact that NST at that time did not have competence on $3 \mathrm{G}$ video-conferencing for mobile phones. This situation lead to the project being alone in choosing and shaping the solution. We argue that these aspects both influenced the changing process and the resulting solution's generativity.

\subsection{Trying to Build on the Installed Base}

The existing health network (NHN, the Norwegian Health Network) was a broadband network that allowed secure communication within the health sector, but it did not accommodate communication to private homes. This might have been technically possible for specific projects, but was not offered as a routine service. Moreover, the health network had not yet incorporated mobile technologies and the fixed- line network. Thus, according to the first of Zittrain's aspects of generativity, leverage of tasks, the existing communication network leveraged communication only for a limited number of users and for the traditional set of communication technologies. It allowed secure and fast communication, but only between those already on the network, using the technologies that were supported. This may work for the CYP offices but could not have included the families in a large-scale, routine solution. With regard to adaptability, the broadband network is a relative generic highway with lots of possibilities. However, its use is regulated, for instance, security considerations led to the requirement that initiative transactions had to be taken from inside (pull rather than push-based communication). The existing information infrastructure is, therefore, adaptable for the prevailing paradigm (i.e., the hospital-centered model). Moreover, the project history showed limited accessibility of the information infrastructure. While access to the broadband network might in principle have been possible, due to reorganization, changing responsibilities, and lack of resources, the county's IT department refused to support the project: It did not even release basic information about the infrastructure, which made the existing infrastructure less accessible, even for the employees in the health care sector. This effectively barred any external innovation from building directly upon it. It is difficult to assess to what degree the situation would have been different if the IT department had been able and willing to cooperate. For all practical purposes, we can regard the existing health network as closed for this innovation, and thus not particularly generative. The aspect of ease of mastery is also difficult to assess since there was no practical openness to interact with the infrastructure. While it would be available for use by the CYP specialists, it would not be available for technical modifications and tinkering. Even if it had been open for use, the adaptations required would have been technically complicated and would have required assistance from technically skilled personnel. Thus it was not easily mastered. The security aspects motivated a cautious progress in these kinds of use areas. When these factors are coupled with a stronger focus on regional and national standardization and centralization of ICT initiatives, we may see that there are internal barriers to innovation initiatives.

The resulting information infrastructure is not particularly generative information. Consequently, the new solution is not built directly upon the existing information infrastructure, but outside it, as a separately financed and technically independent communication path. Thus the non-generativity of the existing information infrastructure, due to 
the inertia of its installed base, actually spurred a more radical form for innovation, but in a decoupled way. The fact that the IT department relinquished control and withdrew left the space wide open for the users' participation and impact on shaping the solution. A different configuration of the assemblage would have resulted in a process that would have been conditioned in a different way, and probably would have been shaped more by the institutionalized communication patterns and solutions. This is evident from the post hoc comments to the solution from the regional IT department.

\subsection{The New Solution: Will it Be Generative?}

While in the last section we used the generativity concept to retrospectively analyze the reasons for the project's departure, here we want to employ the concept in a projective way. We will try to analyze the new care model and the technology and ask whether the solution may be generative for further innovation and use. To some degree, this will be an extrapolation from the existing system, rather than an empirically based analysis.

Leverage seemed to be important for the users who wanted mobile technology as a supplement in the therapy. They expected a tighter follow-up, with less travel and waiting time. The new mobile application allowed the user to accomplish tasks that couldn't otherwise be accomplished, such as immediate reporting and feedback. Also, the aspect of adaptability seemed relevant. The mobile technology has, in this case, been easy to modify for new purposes, to support psychiatric treatment through structured and nonstructured communication. The application allowed the modification of registration forms and report formats by the parents themselves. Ease of mastery defines how easy is it for broad audiences to both adopt and adapt a technology. The previous paper forms were readily mastered by the users, and they were also flexible and adaptable. The participant users in the group expressed clearly that they were familiar with the use of the mobile phone in general, and that participating in application development was meaningful. This application using mobile phones was supposed to have a lower entrance barrier than videoconferencing or PC-based systems. The users' participation in the development process, coupled with the absence of the established IT actors, resulted in the new application being adaptable and leveraging tasks. The resulting application has low technical complexity. Finally, accessibility, signifies the degree to which a person can come to control and use the technology. The mobile solution is available for the pilot users as a routine tool and allows the reporting forms to be adapted by the users themselves. The direct contact with the technology vendor who hosts the application also allows adaptations to be easily achieved.

The process of development led to the users having a significant role in defining the solution. For instance, the choice of mobile telephones rather than computers as the basic tool enabled user participation. This again led to a technically noncomplex application with intuitive usage patterns. Moreover, it is likely that the solution in general can be used in other geographical areas that may have a different organization of CYP services. It may also be adapted to serve other health care domains, especially those domains where self-monitoring and reporting are important. With respect to different diseases, information needs, information contents, and communication patterns may vary significantly. Generally in these usage settings the challenge is the need for security, which has priority, and is likely to influence the potential for unlimited innovation of usage patterns. 


\section{CONCLUDING REMARKS}

We have described the process where the preexisting systems and models (the institutionalized assemblages) could not easily encompass user-driven innovations. Thus the solution was developed outside the existing healthcare network and outside the institutionalized locations for technology innovation. The controversies that emerged are illustrative of the types of challenges fundamental transformations of service models may encounter. It is telling to note that the most problematic aspects in this case were related to the inertia of the installed base of the technological infrastructure, rather than administrative or regulative aspects of the organization. We do not believe this is the end of the story; rather it is a snapshot during a particularly illustrative moment in the evolutionary history of the health sector's information infrastructure of Finnmark. The timing is crucial to be able to identify these controversies, which are often black-boxed when one studies only the resulting solution after the project has finished. Even though we believe that the involved health authorities (Health Finnmark and Northern Norway Regional Health Authority) will find an adequate solution in the end, we also believe that the generative characteristics of the new solution will be a lasting inheritance of this particular process. Since this new solution was developed in a somewhat marginal position, the stronger stakeholders did not have the opportunity to reproduce the institutionalized models and solutions. Thus, the initial stages of the project are interesting both for practical and theoretical reasons.

We have argued that because of the non-generativity of the existing installed base, the new solution emerged with larger potential for future generativity than it would have if the process had been different. The installed base is a central resource for any change attempt, and new solutions depart from and build on it in specific ways. This should constitute relevant topics for future research, both within this particular project and in other attempts to study the ongoing transformations of organizations and societies with information and communication technologies.

\section{References}

Abbate, J. 1994. "The Internet Challenge: Conflict and Compromise in Computer Networking," in Changing Large Technical Systems, J. Summerton (ed.), Boulder, CO: Westview Press, pp. 193-210.

Arthur, W. B. 1989. "Competing Technologies, Increasing Returns, and Lock-In by Historical Events," The Economic Journal (99:394), pp. 116-131.

Ball M. J, and Lillis J. 2001. "E-Health: Transforming the Physician/Patient Relationship," International Journal of Medical Informatics (61:1), pp. 1-10.

Brennan, P., and Safran, C. 2003. "Report of Conference Track 3: Patient Empowerment," International Journal of Medical Informatics (69), pp. 301-304.

Baskerville, R. 1999. "Investigating Information Systems with Action Research," Communications of the AIS (2:19), pp. 1-32.

Ciborra, C. 1994. "The Grassroots of IT and Strategy," in Strategic Information Systems: A European Perspective, C. Ciborra and T. Jelassi (eds.), Chichester, England: John Wiley and Sons, pp. 3-24.

Checkland, P. 1991. "From Framework through Experience to Learning: The Essential Nature of Action Research," in Information Systems Research: Contemporary Approaches and 
Emergent Traditions, H-E. Nissen, H. K. Klein, and R. A. Hirschheim (eds.), Amsterdam: North-Holland, pp. 397-403.

David, P. A. 2005. "The Beginnings and Prospective Ending of 'End-to-End': An Evolutionary Perspective on the Internet's Architecture,' Industrial Organization from Economics Working Paper Archive (EconWPA) (http://econpapers.repec.org/paper/wpawuwpio/0502012.htm).

Hanseth, O., and Aanestad, M. 2003: "Design as Bootstrapping: On the Evolution of ICT Networks in Health Care," Methods of Information in Medicine (42:4), pp. 384-391.

Hanseth, O., Ciborra, C., and Braa, K. 2001. "The Control Devolution: ERP and the Side Effects of Globalization," SIGMIS Database (32:4), pp. 34-46.

Hanseth, O., and Lyytinen, K. 2004. "Theorizing about the Design of Information Infrastructures: Design Kernel Theories and Principles," Sprouts: Working Papers on Information Environments, Systems and Organizations (4:4), pp. 207-241.

Hughes, T. P. 1983. Networks of Power: Electrification in Western Society 1880-1930, Baltimore, MD: The John Hopkins University Press.

Lanzara, G. F. 2008. "Mapping the Encounter Between ICT and Institutions: The Emergence of Techno-Institutional Assemblages," in ICT and Innovation in the Public Sector: European Perspectives on the Making of e-Government, F. Contini and G. F. Lanzara (eds.), Basingstoke, England: Palgrave MacMillan (forthcoming).

Monteiro, E. 1998. "Scaling Information Infrastructure: The Case of the Next Generation IP in the Internet," The Information Society (14:3), pp. 229-245.

Monteiro, E., and Hanseth, O. 1995. "Social Shaping of Information Infrastructure: On Being Specific about the Technology," in Information Technology and Changes in Organizational Work, W. J. Orlikowski, G. Walsham, M. R. Jones, and J. I. DeGross (eds.), London: Chapman \& Hall, pp. 325-343.

Nielsen, P. 2006. Conceptual Framework of Information Infrastructure Building: A Case Study of the Development of a Content Service Platform for Mobile Phones in Norway, unpublished Ph.D. thesis, University of Oslo.

Sassen, S. 2006. Territory, Authority, Rights: From Medieval to Global Assemblages, Princeton, NJ: Princeton University Press.

Star, S. L., and Ruhleder, K 1996. "Steps Toward an Ecology of Infrastructure: Design and Access for Large Information Spaces," Information Systems Research (17:1), pp. 111-134.

Sussman, G. L., and Evered, R. D. 1978. "An Assessment of the Scientific Merits of Action Research," Administrative Sciences Quarterly (23), pp. 582-603.

Zittrain, J. 2006. “The Generative Internet," Harward Law Review (119:7), May , pp. 1974-2040 (http://eecs.harvard.edu/qr48/jzgenerativity.pdf).

\section{About the Authors}

Synnove Thomassen Andersen is a Ph.D. student at the Department of Informatics, University of Oslo, Norway. She has worked as a Child Welfare Worker, and within informatics at Finnmark University College. Her research interests are related to global infrastructures, specifically in health care. Synnøve can be reached at synnovet@hifm.no.

Margunn Aanestad is a researcher at the Department of Informatics, University of Oslo, Norway. She worked in the health care and telecommunications fields before her doctoral study of surgical telemedicine. Her research interests are broadly related to large-scale information infrastructures, specifically in health care. Margunn can be reached at margunn@ifi.uio.no. 